\title{
Paraneoplastic Signs in Bladder Transitional Cell Carcinoma: An Unusual Presentation
}

\author{
Jamie Phillip Schlarbaum, MD; John Fenyk, MD; Daniel Miller, MD; Lauren Becker O’Neill, MD
}

\section{PRACTICE POINTS}

- Paraneoplastic conditions may present secondary to urologic malignancy. Providers should perform thorough malignancy screening, including urologic cystoscopy, in patients presenting with paraneoplastic signs and no identified malignancy.

- Oral retinoids, such as acitretin, may be used as an adjuvant treatment to treat paraneoplastic cutaneous symptoms. The definitive treatment is malignancy management.

To the Editor:

A 40-year-old Somalian man presented to the dermatology clinic with lesions on the eyelids, tongue, lips, and hands of 8 years' duration. He was a former refugee who had faced considerable stigma from his community due to his appearance. A review of systems was remarkable for decreased appetite but no weight loss. He reported no abdominal distention, early satiety, or urinary symptoms, and he had no personal history of diabetes mellitus or obesity. Physical examination demonstrated hyperpigmented velvety plaques in all skin folds and on the genitalia. Massive papillomatosis of the eyelid margins, tongue, and lips also was noted (Figure 1A). Flesh-colored papules also were scattered across the face. Punctate, flesh-colored papules were present on the volar and palmar hands (Figure 2A). Histopathology demonstrated pronounced papillomatous epidermal hyperplasia with negative human papillomavirus (HPV) type 16 and HPV-18 DNA studies. Given the appearance of malignant acanthosis nigricans with oral and conjunctival features, cutaneous papillomatosis, and tripe palms, concern for underlying malignancy was high. Malignancy workup, including upper and lower endoscopy as well as serial computed tomography scans of the chest, abdomen, and pelvis, was unrevealing.

Laboratory investigation revealed a positive Schistosoma IgG antibody (0.38 geometric mean egg count) and peripheral eosinophilia $\left(1.09 \times 10^{3} / \mu \mathrm{L}\right)$, which normalized after praziquantel therapy. With no malignancy identified over the preceding 6-month period, treatment with acitretin $50 \mathrm{mg}$ daily was initiated based on limited literature support. ${ }^{1-3}$ Treatment led to reduction in the size and number of papillomas (Figure 1B) and tripe palms (Figure 2B) with increased mobility of hands, lips, and tongue. The patient underwent oculoplastic surgery to reduce the papilloma burden along the eyelid margins. Subsequent cystoscopy 9 months after the initial presentation revealed low-grade transitional cell carcinoma of the bladder. Intraoperative mitomycin $\mathrm{C}$ led to tumor shrinkage and, with continued treatment with daily acitretin, dramatic improvement of all cutaneous and mucosal symptoms (Figure 1C and Figure 2C). To date, his cutaneous symptoms have resolved.

This case demonstrated a unique presentation of multiple paraneoplastic signs in bladder transitional cell carcinoma. The presence of malignant acanthosis nigricans (including oral and conjunctival involvement), cutaneous papillomatosis, and tripe palms have been

Drs. Schlarbaum and Miller are from the Department of Dermatology, University of Minnesota, Minneapolis. Drs. Fenyk and O’Neill are from Park Nicollet Health Services, St. Louis Park, Minnesota.

The authors report no conflict of interest.

Correspondence: Jamie Phillip Schlarbaum, MD, University of Minnesota Medical School, Department of Dermatology, 516 Delaware St SE, Mail Code 98, Phillips-Wangensteen Bldg, Ste 4-240, Minneapolis, MN 55455 (schla255@umn.edu).

doi: $10.12788 /$ cutis. 0371 

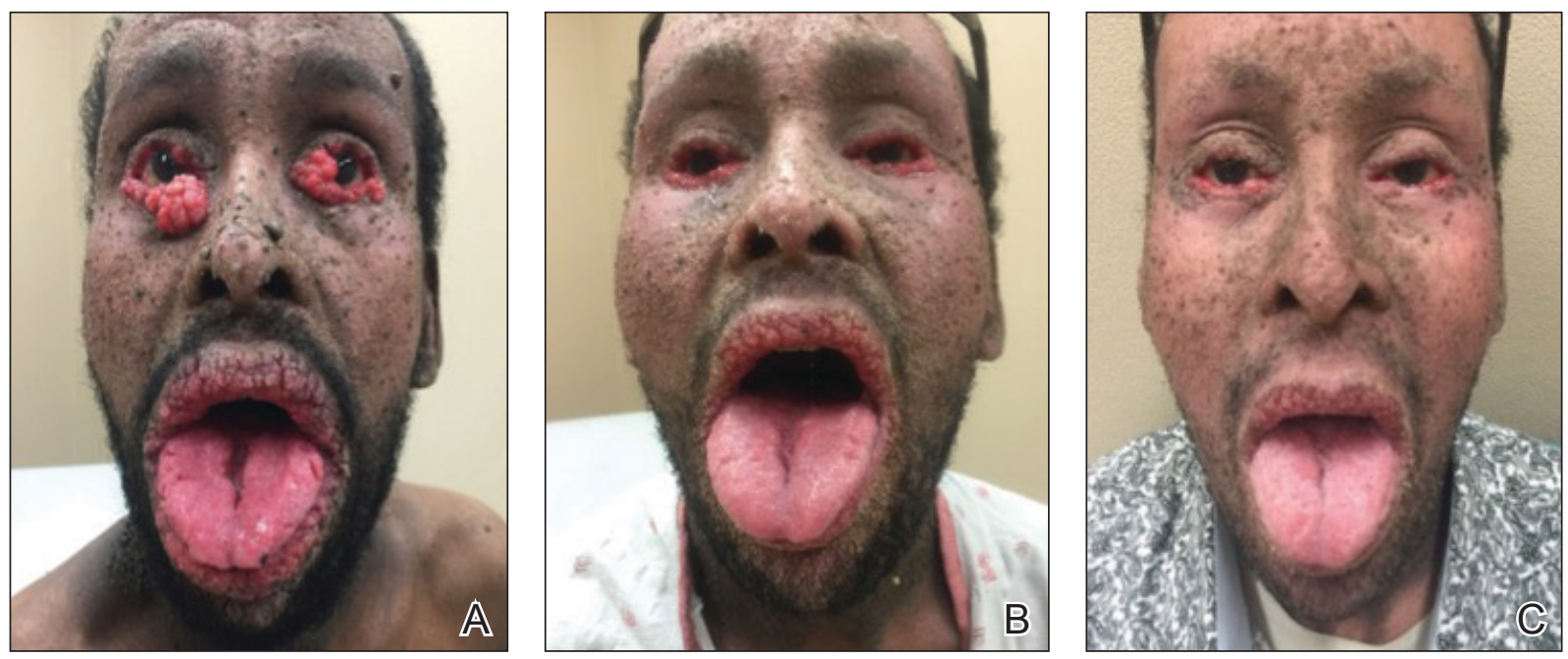

FIGURE 1. A-C, Progressive mucocutaneous papillomatosis and oral/conjunctival malignant acanthosis nigricans at initial presentation, after 4 months of treatment with acitretin $50 \mathrm{mg}$ daily, and 6 weeks following intraoperative mitomycin $\mathrm{C}$ after 9 months of continued treatment with daily acitretin.
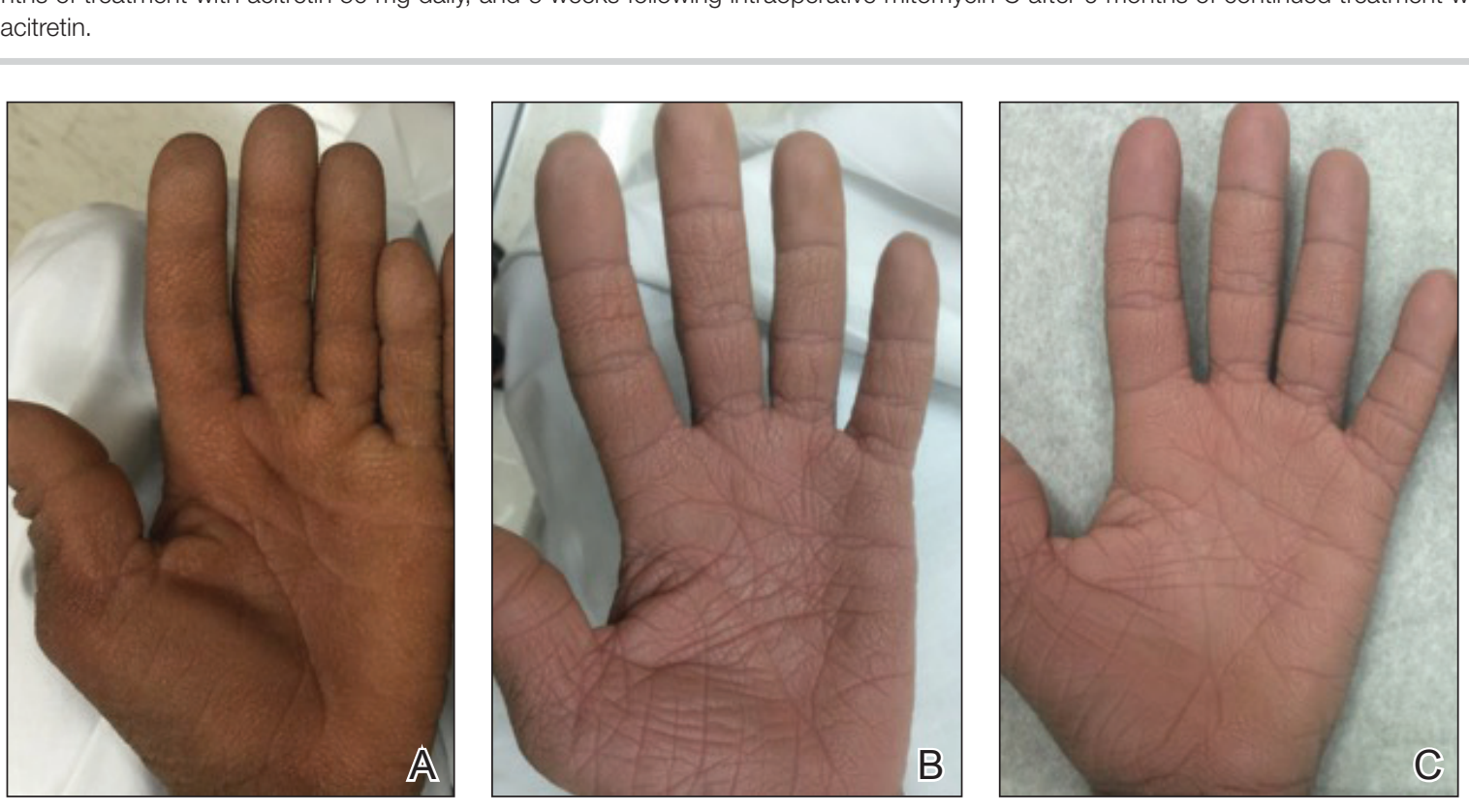

FIGURE 2. A-C, Tripe palms on initial presentation, after 4 months of treatment with acitretin $50 \mathrm{mg}$ daily, and 6 weeks following intraoperative mitomycin $\mathrm{C}$ after 9 months of continued treatment with daily acitretin.

individually documented in various types of gastric malignancies. ${ }^{4}$ Acanthosis nigricans often is secondary to diabetes and obesity, presenting with diffuse, thickened, velvety plaques in the flexural areas. Malignant acanthosis nigricans is a rare, rapidly progressive condition that often presents over a period of weeks to months; it almost always is associated with internal malignancies. It often has more extensive involvement, extending beyond the flexural areas, than typical acanthosis nigricans. ${ }^{4}$ Oral involvement can be either hypertrophic or papillomatous; papillomatosis of the oral mucosa was reported in over $40 \%$ of malignant acanthosis nigricans cases $(\mathrm{N}=200) .{ }^{5}$ Cases with conjunctival involvement are less common. ${ }^{6}$ Although malignant acanthosis nigricans often is codiagnosed with a malignancy, it can precede the cancer diagnosis in some cases. ${ }^{7,8} \mathrm{~A}$ majority of cases are associated with adenocarcinomas of the gastrointestinal tract. ${ }^{4}$ Progressive mucocutaneous papillomatosis also is a rare paraneoplastic condition that most commonly is associated with gastric adenocarcinomas. Progressive mucocutaneous papillomatosis often presents rapidly as verrucous growths on cutaneous surfaces (including the hands and face) but also can affect mucosal surfaces such as the mouth and conjunctiva. ${ }^{9-11}$ Tripe palms are characterized by exaggerated dermatoglyphics with diffuse palmar ridging and hyperkeratosis. Tripe palms most 
often are associated with pulmonary malignancies. When tripe palms are present with malignant acanthosis nigricans, they reflect up to a one-third incidence of gastrointestinal malignancy. 12,13

Despite the individual presentation of these paraneoplastic signs in a variety of malignancies, synchronous presentation is rare. A brief literature review only identified 6 cases of concurrent acanthosis nigricans, tripe palms, and progressive mucocutaneous papillomatosis with an underlying gastrointestinal malignancy.,11,14-17 Two additional reports described tripe palms with oral acanthosis nigricans and progressive mucocutaneous papillomatosis in metastatic gastric adenocarcinoma and renal urothelial carcinoma. ${ }^{2,18}$ An additional case of all 3 paraneoplastic conditions was reported in the setting of metastatic cervical cancer (HPV positive). ${ }^{19}$ Per a recent case report and literature review, ${ }^{20}$ there have only been 8 cases of acanthosis nigricans reported in bladder transitional cell carcinoma, ${ }^{20-27}$ half of which have included oral malignant acanthosis nigricans. ${ }^{20-23}$ Only one report of concurrent cutaneous and oral malignant acanthosis nigricans and triple palms in the setting of bladder cancer has been reported. ${ }^{20}$ Given the extensive conjunctival involvement and cutaneous papillomatosis in our patient, ours is a rarely reported case of concurrent malignant mucocutaneous acanthosis nigricans, tripe palms, and progressive papillomatosis in transitional cell bladder carcinoma. We believe it is imperative to consider the role of this malignancy as a cause of these paraneoplastic conditions.

Although these paraneoplastic conditions rarely cooccur, our case further offers a common molecular pathway for these conditions. ${ }^{28}$ In these paraneoplastic conditions, the stimulating factor is thought to be tumor growth factor $\alpha$, which is structurally related to epidermal growth factor (EGF). Epidermal growth factor receptors (EGFRs) are found in the basal layer of the epidermis, where activation stimulates keratinocyte growth and leads to the cutaneous manifestation of symptoms. ${ }^{28}$ Fibroblast growth factor receptor 3 mutations are found in most noninvasive transitional cell tumors of the bladder. ${ }^{29}$ The fibroblast growth factor pathway is distinctly different from the tumor growth factor $\alpha$ and EGF pathways. ${ }^{30}$ However, this association with transitional cell carcinoma suggests that fibroblast growth factor receptor 3 also may be implicated in these paraneoplastic conditions.

Our patient responded well to treatment with acitretin $50 \mathrm{mg}$ daily. The mechanism of action of retinoids involves inducing mitotic activity and desmosomal shedding. ${ }^{31}$ Retinoids downregulate EGFR expression and activation in EGF-stimulated cells. ${ }^{32}$ We hypothesize that these oral retinoids decreased the growth stimulus and thereby improved cutaneous signs in the setting of our patient's transitional cell cancer. Although definitive therapy is malignancy management, our case highlights the utility of adjunctive measures such as oral retinoids and surgical debulking. While previous cases have reported use of retinoids at a lower dosage than used in this case, oral lesions often have only been mildly improved with little impact on other cutaneous symptoms. ${ }^{1,2}$ In one case of malignant acanthosis nigricans and oral papillomatosis, isotretinoin $25 \mathrm{mg}$ once every 2 to 3 days led to a moderate decrease in hyperkeratosis and papillomas, but the patient was lost to follow-up. ${ }^{3}$ Our case highlights the use of higher daily doses of oral retinoids for over 9 months, resulting in marked improvement in both the mucosal and cutaneous symptoms of acanthosis nigricans, progressive mucocutaneous papillomatosis, and tripe palms. Therefore, oral acitretin should be considered as adjuvant therapy for these paraneoplastic conditions.

By reporting this case, we hope to demonstrate the importance of considering other forms of malignancies in the presence of paraneoplastic conditions. Although gastric malignancies more commonly are associated with these conditions, bladder carcinomas also can present with cutaneous manifestations. The presence of these paraneoplastic conditions alone or together rarely is reported in urologic cancers and generally is considered to be an indicator of poor prognosis. Paraneoplastic conditions often develop rapidly and occur in very advanced malignancies. ${ }^{4}$ The disfiguring presentation in our case also had unusual diagnostic challenges. The presence of these conditions for 8 years and nonmetastatic advanced malignancy suggest a more indolent process and that these signs are not always an indicator of poor prognosis. Future patients with these paraneoplastic conditions may benefit from both a thorough malignancy screen, including cystoscopy, and high daily doses of oral retinoids.

\section{REFERENCES}

1. Stawczyk-Macieja M, Szczerkowska-Dobosz A, Nowicki R, et al. Malignant acanthosis nigricans, florid cutaneous papillomatosis and tripe palms syndrome associated with gastric adenocarcinoma. Postepy Dermatol Alergol. 2014;31:56-58.

2. Lee HC, Ker KJ, Chong W-S. Oral malignant acanthosis nigricans and tripe palms associated with renal urothelial carcinoma. JAMA Dermatol. 2015;151:1381-1383.

3. Swineford SL, Drucker CR. Palliative treatment of paraneoplastic acanthosis nigricans and oral florid papillomatosis with retinoids. J Drugs Dermatol. 2010;9:1151-1153.

4. Wick MR, Patterson JW. Cutaneous paraneoplastic syndromes [published online January 31, 2019]. Semin Diagn Pathol. 2019; 36:211-228.

5. Tyler MT, Ficarra G, Silverman S, et al. Malignant acanthosis nigricans with florid papillary oral lesions. Oral Surg Oral Med Oral Pathol Oral Radiol Endod. 1996;81:445-449.

6. Zhang X, Liu R, Liu $Y$, et al. Malignant acanthosis nigricans: a case report. BMC Ophthalmology. 2020;20:1-4.

7. Curth HO. Dermatoses and malignant internal tumours. Arch Dermatol Syphil. 1955;71:95-107.

8. Krawczyk M, Mykala-Cieśla J, Kolodziej-Jaskula A. Acanthosis nigricans as a paraneoplastic syndrome. case reports and review of literature. Pol Arch Med Wewn. 2009;119:180-183.

9. Singhi MK, Gupta LK, Bansal M, et al. Florid cutaneous papillomatosis with adenocarcinoma of stomach in a 35 year old male. Indian J Dermatol Venereol Leprol. 2005;71:195-196.

10. Klieb HB, Avon SL, Gilbert J, et al. Florid cutaneous and mucosal papillomatosis: mucocutaneous markers of an underlying gastric malignancy. J Clin Oncol. 2013;31:E218-E219. 
11. Yang $\mathrm{YH}$, Zhang RZ, Kang DH, et al. Three paraneoplastic signs in the same patient with gastric adenocarcinoma. Dermatol Online J. 2013;19:18966

12. Cohen PR, Grossman ME, Almeida L, et al. Tripe palms and malignancy. J Clin Oncol. 1989;7:669-678.

13. Chantarojanasiri T, Buranathawornsom A, Sirinawasatien A. Diffuse esophageal squamous papillomatosis: a rare disease associated with acanthosis nigricans and tripe palms. Case Rep Gastroenterol. 2020;14:702-706

14. Muhammad R, Iftikhar N, Sarfraz T, et al. Malignant acanthosis nigricans: an indicator of internal malignancy. J Coll Physicians Surg Pak. 2019;29:888-890.

15. Brinca A, Cardoso JC, Brites MM, et al. Florid cutaneous papillomatosis and acanthosis nigricans maligna revealing gastric adenocarcinoma. An Bras Dermatol. 2011;86:573-577.

16. Vilas-Sueiro A, Suárez-Amor O, Monteagudo B, et al. Malignant acanthosis nigricans, florid cutaneous and mucosal papillomatosis, and tripe palms in a man with gastric adenocarcinoma. Actas Dermosifiliogr. 2015; 106:438-439.

17. Paravina M, Ljubisavljević D. Malignant acanthosis nigricans, florid cutaneous papillomatosis and tripe palms syndrome associated with gastric adenocarcinoma-a case report. Serbian J Dermatology Venereol. 2015;7:5-14.

18. Kleikamp S, Böhm M, Frosch $\mathrm{P}$, et al. Acanthosis nigricans, papillomatosis mucosae and "tripe" palms in a patient with metastasized gastric carcinoma [in German]. Dtsch Med Wochenschr. 2006;131:1209-1213.

19. Mikhail GR, Fachnie DM, Drukker BH, et al. Generalized malignant acanthosis nigricans. Arch Dermatol. 1979;115:201-202.

20. Zhang R, Jiang M, Lei $W$, et al. Malignant acanthosis nigricans with recurrent bladder cancer: a case report and review of literature. Onco Targets Ther. 2021;14:951.

21. Olek-Hrab K, Silny W, Zaba R, et al. Co-occurrence of acanthosis nigricans and bladder adenocarcinoma-case report. Contemp Oncol (Pozn). 2013;17:327-330.
22. Canjuga I, Mravak-Stipetić M, Kopić V, et al. Oral acanthosis nigricans: case report and comparison with literature reports. Acta Dermatovenerol Croat. 2008;16:91-95.

23. Cairo F, Rubino I, Rotundo R, et al. Oral acanthosis nigricans as a marker of internal malignancy. a case report. I Periodontol. 2001;72:1271-1275.

24. Möhrenschlager M, Vocks E, Wessner DB, et al. 2001;165:1629-1630.

25. Singh GK, Sen D, Mulajker DS, et al. Acanthosis nigricans associated with transitional cell carcinoma of the urinary bladder. Indian J Dermatol. 2011;56:722-725.

26. Gohji K, Hasunuma Y, Gotoh A, et al. Acanthosis nigricans associated with transitional cell carcinoma of the urinary bladder. Int J Dermatol. 1994;33:433-435.

27. Pinto WBVR, Badia BML, Souza PVS, et al. Paraneoplastic motor neuronopathy and malignant acanthosis nigricans. Arq Neuropsiquiatr. 2019;77:527.

28. Koyama S, Ikeda K, Sato M, et al. Transforming growth factor-alpha (TGF-alpha)-producing gastric carcinoma with acanthosis nigricans: an endocrine effect of TGF alpha in the pathogenesis of cutaneous paraneoplastic syndrome and epithelial hyperplasia of the esophagus. J Gastroenterol. 1997;32:71-77.

29. Billerey C, Chopin D, Aubriot-Lorton MH, et al. Frequent FGFR3 mutations in papillary non-invasive bladder (pTa) tumors. Am J Pathol. 2001;158:1955-1959.

30. Lee C-J, Lee M-H, Cho Y-Y. Fibroblast and epidermal growth factors utilize different signaling pathways to induce anchorage-independent cell transformation in JB6 Cl41 mouse skin epidermal cells. J Cancer Prev. 2014;19:199-208.

31. Darmstadt GL, Yokel BK, Horn TD. Treatment of acanthosis nigricans with tretinoin. Arch Dermatol. 1991;127:1139-1140.

32. Sah JF, Eckert RL, Chandraratna RA, et al. Retinoids suppress epidermal growth factor-associated cell proliferation by inhibiting epidermal growth factor receptor-dependent ERK1/2 activation. J Biol Chem. 2002;277:9728-9735 